\title{
Life history and fatty acid composition of the marine rotifer Synchaeta cecilia valentina fed different algae
}

\author{
Rafael Oltra $^{1, *}$, Rafael Todolí ${ }^{1}$, Teresa Bosque ${ }^{1}$, Luis M. Lubián ${ }^{2}$, Juan C. Navarro ${ }^{3}$ \\ ${ }^{1}$ Departamento de Microbiología y Ecología, Facultad de Ciencias Biológicas, Universitat de València, Dr. Moliner 50 , \\ 46100 Burjassot (Valencia), Spain \\ ${ }^{2}$ Instituto de Ciencias Marinas de Andalucía (CSIC), Campus Río San Pedro s/n, 11510 Puerto Real (Cadiz), Spain \\ ${ }^{3}$ Instituto de Acuicultura Torre de la Sal (CSIC), Ribera de Cabanes, 12595 Torre la Sal (Castellón), Spain
}

\begin{abstract}
A strain of the marine rotifer Synchaeta cecilia valentina, isolated from 'El Hondo de Elche', a Spanish Mediterranean coastal lagoon, was cultured in the laboratory in $20 \mathrm{ml}$ test tubes, at $20^{\circ} \mathrm{C}$ and $25 \mathrm{ppt}$ salinity and fed with the algae Tetraselmis sp., $T$, chuii, Cryptomonas sp., Rhodomonas salina and $R$. baltica. The effects of these 5 algal diets and 3 food levels $\left(2.1,3.2\right.$ and $4.2 \mu \mathrm{g} \mathrm{ml}^{-1} \mathrm{dry}$ wt) on life history traits of this rotifer were studied in life tables performed with replicated individual cultures of $1 \mathrm{ml}$, at the temperature and salinity mentioned above. Algal diet had a significant effect on both average lifespan $(L S)$ and net reproductive rate $\left(R_{0}\right)$, but food concentration only had an effect on $R_{0}$. Tetraselmis sp. provided the best results: LS ranging from 4.4 to $6 \mathrm{~d}, R_{0}$ from 10.9 to 12.8 offsping female $e^{-1}$, and intrinsic growth rate $(r)$ from 0.84 to $1.12 \mathrm{~d}^{-1} S$. cecilia valentina also grew with the remainder of the algae, except with $R$. baltica. With this alga the rotifer grew only in $500 \mathrm{ml}$ cultures performed at a higher food concentration $\left(5.55 \mu \mathrm{g} \mathrm{ml}^{-1} \mathrm{dry}\right.$ wt). The effect of the algal diet on the fatty acid composition of the rotifers was analysed to infer its nutritional value according to the changes induced by diet. Saturated fatty acids made up 34 to $40 \%$ of total fatty acids, whereas monoenes accounted for 15 to $23 \%$, and polyunsaturated fatty acids constituted 20 to $29 \%$. Main fatty acids were: 16:0 (which ranged from 17 to $22 \%), 18: 0(10$ to $12 \%)$, and $18: 1$ (8.5 to $12 \%)$. In certain algal treatments (both Tetraselmis species), the linolenic acid 18:3n-3 was moderately abundant ( 5 to $9 \%$ ). Eicosapentaenoic acid, 20:5n-3, was markedly lower in rotifers fed with $R$. baltica (less than $3 \%$ ), whereas docosahexaenoic acid, 22:6n-3, was found in a higher proportion in Cryptomonas sp. (4.9\%) and $R$. salina $(3.4 \%)$ treatments. The nutritional value deduced from the lipid composition was similar to that reported in the literature for other rotifers such as Brachionus plicatilis.
\end{abstract}

KEY WORDS: Life table - Growth rate - Tetraselmis - Cryptomonas $\cdot$ Rhodomonas $\cdot$ Fatty acids

\section{INTRODUCTION}

Culture of marine rotifers is difficult and has only been possible with a small number of species, among them Encentrum linnhei (Schmid-Araya 1991), Synchaeta hutchingsi (Brownell 1988), S. cecilia (Egloff 1986, 1988) and S. cecilia valentina (Oltra \& Todolí 1997) as well as the mixohaline species Brachionus plicatilis-B. rotundiformis (Rezeq \& James 1987, Maru-

\footnotetext{
•E-mail: rafael.oltra@uv.es
}

yama et al. 1997), both considered as strains belonging to the same species until recently (Segers 1995). This is clearly different from freshwater rotifer species, where a number of species have been cultured (Pourriot 1965 , May 1987).

The culture of a new species of marine rotifer would be interesting not only for the new knowledge this would bring in terms of the biology of the species, but also due to the possible application of its cultures to aquatic ecotoxicology and aquaculture, in which the only species used up to date is Brachionus plicatilis-B. 
rotundiformis (Lubzens et al. 1989, Snell \& Janssen 1995).

In a recent paper, Oltra \& Todoli (1997) reported the isolation of and first attempts at culturing the marine rotifer Synchaeta cecilia valentina. This species has been found in several harbours, salines and Mediterranean coastal lagoons of the Valencian region (Spain), within a broad range of temperatures $\left(15\right.$ to $\left.28^{\circ} \mathrm{C}\right)$ and salinities (18 to $40 \mathrm{ppt}$ ) at densities of up to $4800 \mathrm{ind}^{\mathrm{l}^{-1}}$ (X. Armengol-Díaz \& R. Oltra unpubl. obs.). S. cecilia valentina has been cultured in the laboratory at 20 and $24^{\circ} \mathrm{C}$, from 20 to $37 \mathrm{ppt}$ salinity, and fed with the alga Tetraselmis suecica at concentrations of 15000 and 25000 cells $\mathrm{ml}^{-1}$. The longest average lifespan (5.6 d) and highest number of offspring per female (9.2) were obtained at $20^{\circ} \mathrm{C}$ and $25 \mathrm{ppt}$, it being fed at low algal concentration.

The first aim of the present work was to carry out life table analyses of Synchaeta cecilia valentina cultured under optimal conditions of temperature and salinity, using 5 algal species as food: Tetraselmis sp., $T$. chuil, Cryptomonas sp., Rhodomonas salina and $R$. baltica. These algae were selected after initial attempts at feeding with the algae Isochrysis galbana, Pavlova lutheri and Nannochloropsis oculata proved to be unsuccessful.

Nutritional 'status' of the rotifer is critical if it is to serve as a nutrient source in aquaculture. One limiting factor in the use of live prey in aquaculture is the presence of adequate amounts of essential fatty acids for marine fish larvae. These are polyunsaturated fatty acids such as eicosapentaenoic acid (20:5n-3) and docosahexaenoic acid (22:6n-3), which are often absent or present in low amounts in the live prey commonly used as larval food. Both fatty acids have been found in varying amounts in the rotifer Brachionus plicatilis, depending on the algal food used in the cultures (Ben Amotz 1987, Frolov et al. 1991). Therefore, the second aim of this work was to study the fatty acid profiles of Synchaeta cecilia valentina cultured with the different algal diets.

Table 1. Food level and its equivalent algal cell concentration (cells $\mathrm{ml}^{-1}$ ) for the 5 microalgae assayed

\begin{tabular}{|c|c|c|c|c|}
\hline \multirow[t]{2}{*}{ Alga } & \multicolumn{3}{|c|}{ Food level ( $\mu \mathrm{g} \mathrm{ml}^{-1}$ dry wt) } & \multirow[t]{2}{*}{$\mu \mathrm{g} / 10^{6}$ cells } \\
\hline & 2.10 & 3.15 & 4.20 & \\
\hline Tetraselmis sp. & 12100 & 18100 & 24200 & $174.1^{\mathrm{a}}$ \\
\hline T. chuii & 11500 & 17300 & 23000 & 182.4 \\
\hline Cryptomonas sp. & 13700 & 20600 & 27500 & 1.52 .8 \\
\hline Rhodomonas salina & 18000 & 27000 & 36000 & 112.9 \\
\hline R. baltica & 22700 & 34000 & 45400 & 92.6 \\
\hline
\end{tabular}

\section{MATERIALS AND METHODS}

The rotifer Synchaeta cecilia valentina was kept in the laboratory in $20 \mathrm{ml}$ test tubes at $20^{\circ} \mathrm{C}, 25$ ppt salinity, $12 \mu \mathrm{E} \mathrm{m}^{-2} \mathrm{~s}^{-1}$ light intensity with a $12: 12 \mathrm{~h}$ light:dark photoperiod, and fed with the algae Tetraselmis sp., $T$. chuii, Cryptomonas sp., Rhodomonas salina and $R$. baltica. Life table analyses were performed on individual rotifer cultures of $1 \mathrm{ml}$ using these 5 algal diets and 3 food levels $(2.10,3.15$ and $4.20 \mu \mathrm{g} \mathrm{ml}^{-1}$ dry wt), at the same temperature, salinity light intensity and photoperiod as described above. Algae were provided by the Culture Collection of Marine Microalgae, of Instituto de Ciencias Marinas de Andalucía (CSIC). Table 1 shows the cellular concentrations equivalent to the respective food level for each alga tested. Culture medium for rotifers and algae was prepared with filtered and sterilized seawater of $38 \mathrm{ppt}$ (Spanish Mediterranean coast) diluted to 25 ppt and fertilized according to Guillard \& Ryther (1962). Algae were grown in $500 \mathrm{ml}$ Erlenmeyer flasks at $20^{\circ} \mathrm{C}$ and $80 \mu \mathrm{E} \mathrm{m} \mathrm{m}^{-2} \mathrm{~s}^{-1}$ light intensity $(12: 12 \mathrm{~h}$ light:dark photoperiod), without aeration. Cultures were renewed daily to maintain a continuous exponential growth phase.

The procedure used for each of the 15 experimental assays was as follows: Pre-experimental cultures were maintained under the 'experimental' conditions for at least $1 \mathrm{wk}$ in $20 \mathrm{ml}$ test tubes at low population density $\left(<5\right.$ ind. $\left.\mathrm{ml}^{-1}\right)$. From these cultures, approximately 100 egg-bearing females were selected at random and placed in glass wells $\left(2\right.$ females $\mathrm{ml}^{-1}$ ). After $12 \mathrm{~h}$, 60 newborn females were isolated and cultured individually throughout their lifetime in 24 -well plates with $1 \mathrm{ml}$ of fresh culture medium in each well. Offspring were counted every $24 \mathrm{~h}$ and mothers were transferred to new trays with freshly prepared medium and food. Algal concentrations in exponentially growing cultures were determined with a haemocytometer and diluted to the desired food level. After daily adjustment of food level, the algae, all of which are motile, were homogenously distributed in culture wells. Rotifers moved through the volume without showing a preference for a particular site. Just before the renewal of the medium, a small percentage of the algae, approximately $10 \%$, rennained sedimented at the bottom. This low settling was observed in all algal treatments and had no apparent incidence in the performance of the cultures.

From survival and fecundity schedules, the following demographic parameters were calculated: average iffespan $(L S)$. average number of female descendants per fernale lifetime $\left(R_{0}\right)$, average age of 
offspring production $\left(T_{c}\right)$, intrinsic rate of population increase ( $r$ ) [calculated as $r=\ln R_{0} / T_{\mathrm{c}}$ ], age-specific survival $\left(l_{x}\right)$, age-specific fecundity $\left(m_{x}=\right.$ newborns per female) and age-specific mortality $\left(q_{x}=\right.$ deaths/living females) (Carey 1993). The effects of algae and food level on $L S$ and $R_{0}$ were examined using a factorial design for a univariate ANOVA.

For lipid analyses, triplicate $500 \mathrm{ml}$ cultures of Synchaeta cecilia valentina were grown under the same conditions and with the same algal foods. Cultures with Tetraselmis suecica were also grown, since this alga has been used successfully to feed $S$. cecilia valentina (Oltra \& Todoli 1997). An air pump that worked for $15 \mathrm{~min}$ each hour was used to keep the algae suspended in the cultures. No continuous aeration was provided, in order to avoid the risk of damaging the rotifers since their resistance is unknown. The initial algal concentration was $3.15 \mu \mathrm{g} \mathrm{ml}^{-1}$ dry wt, with the exception of Rhodomonas baltica $15.55 \mu \mathrm{g} \mathrm{ml}^{-1}$, 60000 cells ml $l^{-1}$ ). Initial rotifer density was 1 ind. $\mathrm{ml}^{-1}$. When the density was higher than 50 ind. $\mathrm{ml}^{-1}$, the cultures were filtered through a Nytal $45 \mu \mathrm{m}$ mesh, washed with diluted sterilised marine water (25 ppt) and transferred to vials filled with chloroform:methanol $(2: 1, v: v)$ with $0.01 \%$ (w:v) butylated hydroxytoluene (BHT). The vials were capped after flushing with nitrogen and stored at $-80^{\circ} \mathrm{C}$ until the fatty acid analyses were performed.

Lipid and fatty acid analyses were carried out following the procedures described in Navarro et al. (1992). Since rotifers were stored in solvent once harvested from the cultures, no data are available for the absolute percentage of lipids. Methyl esters were injected in a Fisons 8000 series gas chromatograph fitted with an on-column injector, a Tracksil capillary column $(30 \mathrm{~m}$, $0.25 \mathrm{~mm}, 0.15 \mu \mathrm{m}$ film thickness) and a flame ionisation detector. Helium was used as the carrier gas. Oven temperatures were programmed from 50 to $180^{\circ} \mathrm{C}$ at $40^{\circ} \mathrm{C} \mathrm{min}{ }^{-1}$ and from 180 to $220^{\circ} \mathrm{C}$ at $3^{\circ} \mathrm{C} \mathrm{min}^{-1}$, and then were held at $220^{\circ} \mathrm{C}$ for $20 \mathrm{~min}$. Peaks were identified and characterised by comparison with known standards.

The most discriminating variables, i.e., those fatty acids common to all algal treatments giving significant differences after univariate ANOVA $(<14: 0,14: 0,16: 1$, $20: 1,20: 4 n-6,22: 6 n-3)$, were entered in a discriminant analysis model (Navarro et al. 1995) using the algal treatments as the discriminating variable. Prior to the analysis, percentage data were log transformed.

\section{RESULTS}

The effects of algal diet and food concentration on the survival and age-specific fecundity of Synchaeta cecilia valentina are shown in Fig. 1. The maximum lifespan of the rotifer is longer when cultured with the algae Tetraselmis sp., T. chuil and Rhodomonas baltica (up to $11 \mathrm{~d}$ ) than when cultured with $R$. salina (up to $9 \mathrm{~d}$ ) or with Cryptomonas sp. (up to $7 \mathrm{~d}$ ). The lowest values for age-specific fecundity $\left(m_{x}\right)$ appear with $R$. baltica: maximum values from 0.3 to 1 , depending on the food concentration. These values are, moreover, obtained at late ages (Days 7 to 9 ) when the number of surviving females is low, which implies a low number of new borns. When feeding with the algae Cryptomonas sp., $T$. chuii, and Tetraselmis sp., the $m_{x}$ values obtained are progressively greater and appear at earlier ages (Days $1,2,3,4$ ). The highest values are for the alga Tetraselmis sp., with which a maximum range from 2.4 to 4.5 is reached. Age-specific mortality $\left(q_{x}\right)$ tends to be low on first days as long as the age-specific survival $l_{x}$ reaches high values and increases at late ages. This tendency can be clearly appreciated with the Tetraselmis sp. treatment and to a lesser extent with $T$. chuii. More variations were registered with the rest of the algae due to the high mortalities which occurred at early ages.

In general, the maximum lifespan is longer with the intermediate food level, and shorter when the food concentration is low. With the higher food concentration, the lifespan is either reduced by 1 or $2 \mathrm{~d}$ with respect to the medium concentration (Tetraselmis sp., T. chuii, Cryptomonas sp., Rhodomonas baltica) or presents the same values ( $R$. salina). The $m_{x}$ values tend to increase along with the food concentration (except with the alga Cryptomonas sp.), and the maxima occur earlier (with the exception of the alga $R$. baltica).

In Table 2 , the average lifespan $(L S)$ and average number of offspring per female $\left(R_{0}\right)$ are shown for each of the 15 assays. It can be seen that the effect of food type is highly significant for both parameters (Table 3). LS is longer in cultures with the algae Tetraselmis sp. (from 4.4 to $6 \mathrm{~d}$ ) and $T$. chuii (from 3.7 to $5.1 \mathrm{~d}$ ) than with the others. The lowest values are for the alga Cryptomonas sp. $(1.6$ to $2.0 \mathrm{~d}) . R_{0}$ is also higher with both Tetraselmis species: over 10 in all the assays with Tetraselmis sp. and from 3.3 to 6.8 with $T$. chuii. This parameter is greatly reduced, and less than 1, in all treatments with Rhodomonas baltica, which indicates a negative growth in Synchaeta cecilia valentina.

The effect of food concentration, especially on $L S$, is less clear (Tables $2 \& 3$ ). With the algae Rhodomonas salina, Cryptomonas sp. and Tetraselmis chuii, both $L S$ and $R_{0}$ increase as the food concentration increases in the density range used, whereas with $R$. baltica and Tetraselmis sp. LS decreases when the algal concentration increases and $R_{0}$ reaches its maximum values with the intermediate food concentration. 
|x Tetraselmis sp.

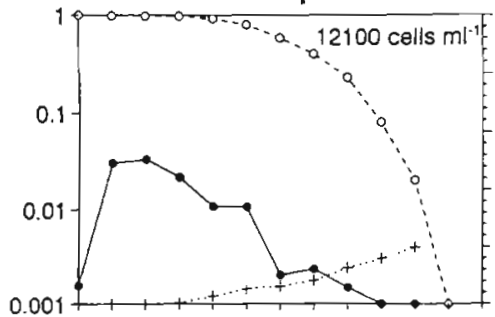

Ix Tetraselmis chuii

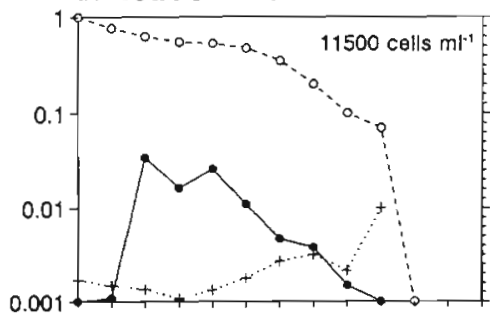

ix Cryptomonas sp.

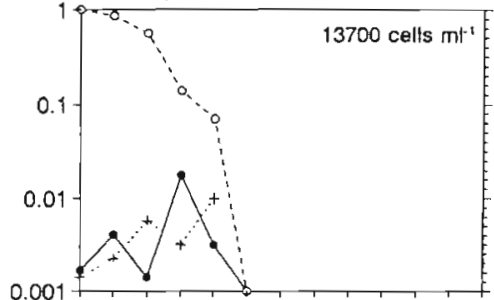

Rhodomonas salina

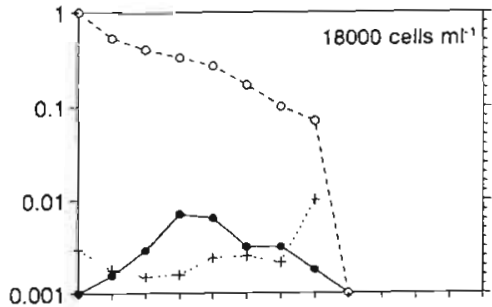

Ix Rhodomonas baltica

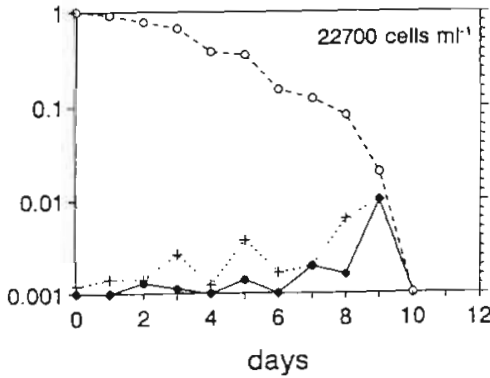

Ix
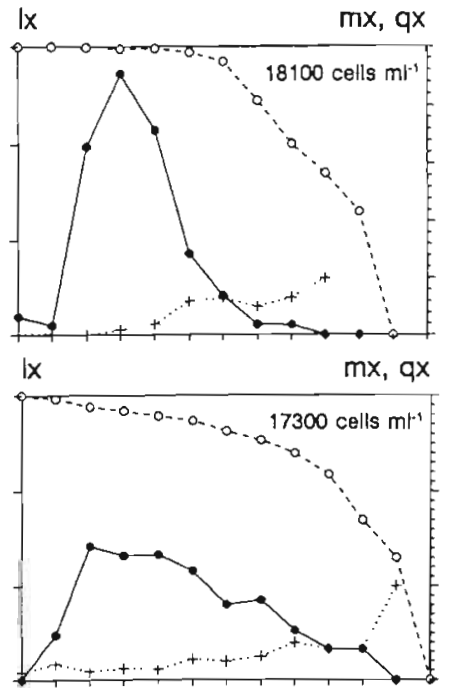

$\mathrm{mx}, \mathrm{qx}$

$1 x$

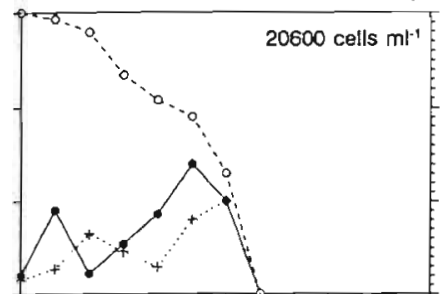

Ix

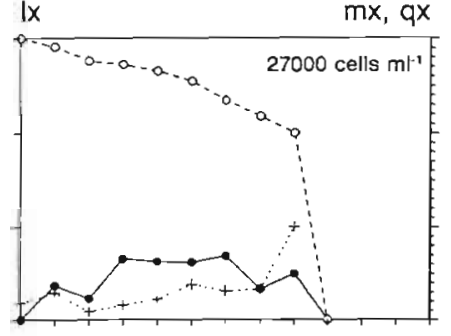

$\mathrm{mx}, \mathrm{qx}$

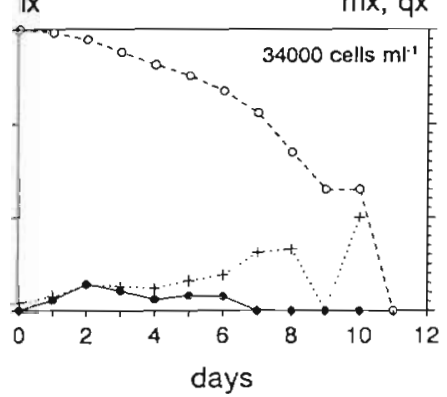

ix
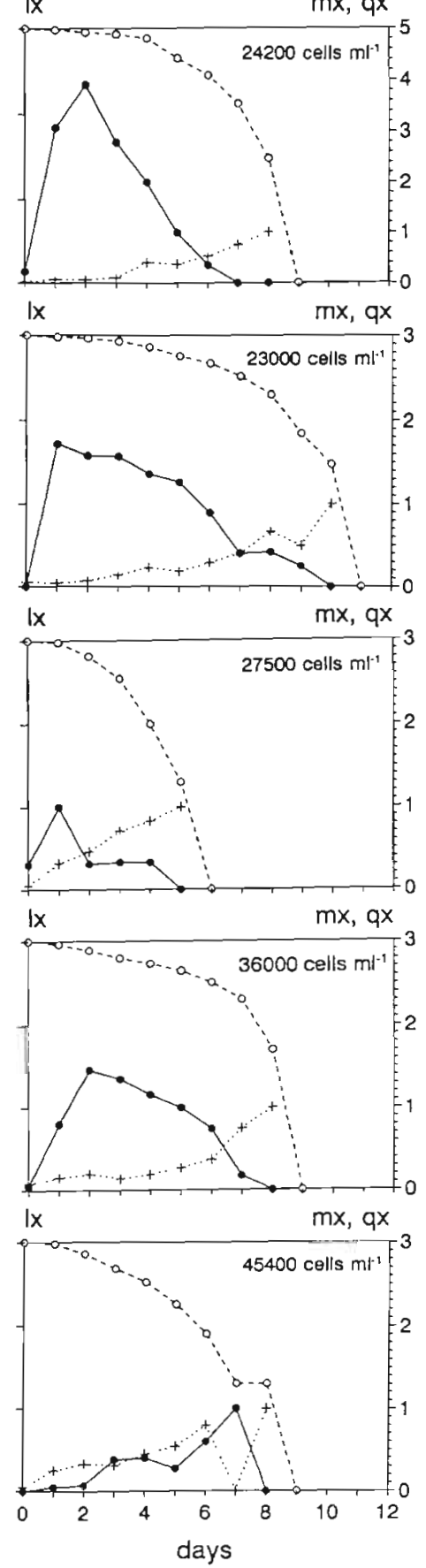

Fig. 1. Age-specific survival $\left(l_{x}, 0\right)$, fecundity $\left(m_{x}, \bullet\right)$ and mortality $\left(q_{x},+\right)$ for Synchaeta cecilia valentina fed with different algae at several food concentrations. Note that treatment with Tetraselmis sp. has a different scale for $m_{x}$ and $q_{x}$

Fig. 2 shows the variations of $R_{0}$, cohort generation time $\left(T_{c}\right)$ and intrinsic rate of population increase $(r)$. The lowest values of $T_{c}$ appear with Cryptomonas sp. which also gives the lowest $L S$ values. Tetraselmis sp. also offers low values of $T_{c}$, indicating that offspring appear early. Rhodomonas baltica shows the highest values (except with the medium food concentration) in concordance with the increase in age-specific fecun- dity at the end of life (Fig. 1). The variations in $T_{c}$ relative to food concentration are not so clear. It does, however, seem that reproduction of Synchaeta cecilia valentina is earlier (lower $T_{\mathrm{c}}$ values) with intermediate or high concentrations.

$I$ varies together with $R_{0}$. The greatest values are obtained with Tetraselmis sp. $\left(0.84\right.$ to $\left.1.12 \mathrm{~d}^{-1}\right)$, and the lowest with Rhodomonas baltica $\left(-0.18\right.$ to $\left.-0.33 \mathrm{~d}^{-1}\right)$. 
Table 2. Average lifespan (LS) and average number of descendants per female $\left(R_{0}\right)$, with their respective standard errors (SE), for Synchaeta cecilia valentina grown at different food levels on 5 different algae

\begin{tabular}{|c|c|c|c|c|c|c|}
\hline Alga & $\begin{array}{c}\text { Food level } \\
\left(\mu \mathrm{g} \mathrm{ml}^{-1} \text { dry wt }\right)\end{array}$ & $\mathrm{n}$ & $L S$ & $\mathrm{SE}$ & $R_{0}$ & $\mathrm{SE}$ \\
\hline Tetraselmis sp. & $\begin{array}{l}2.10 \\
3.15 \\
4.20\end{array}$ & $\begin{array}{l}60 \\
60 \\
60\end{array}$ & $\begin{array}{l}6.0 \\
4.9 \\
4.4\end{array}$ & $\begin{array}{l}0.3 \\
0.2 \\
0.2\end{array}$ & $\begin{array}{l}10.9 \\
12.8 \\
11.3\end{array}$ & $\begin{array}{l}0.4 \\
0.5 \\
0.7\end{array}$ \\
\hline Tetraselmis chuii & $\begin{array}{l}2.10 \\
3.15 \\
4.20\end{array}$ & $\begin{array}{l}60 \\
59 \\
60\end{array}$ & $\begin{array}{l}3.7 \\
4.7 \\
5.1\end{array}$ & $\begin{array}{l}0.4 \\
0.4 \\
0.3\end{array}$ & $\begin{array}{l}3.3 \\
4.7 \\
6.8\end{array}$ & $\begin{array}{l}0.4 \\
0.5 \\
0.5\end{array}$ \\
\hline Cryptomonas sp. & $\begin{array}{l}2.10 \\
3.15 \\
4.20\end{array}$ & $\begin{array}{l}60 \\
60 \\
60\end{array}$ & $\begin{array}{l}1.6 \\
1.9 \\
2.0\end{array}$ & $\begin{array}{l}0.1 \\
0.2 \\
0.1\end{array}$ & $\begin{array}{l}1.0 \\
1.4 \\
1.6\end{array}$ & $\begin{array}{l}0.2 \\
0.2 \\
0.2\end{array}$ \\
\hline Rhodomonas salina & $\begin{array}{l}2.10 \\
3.15 \\
4.20\end{array}$ & $\begin{array}{l}60 \\
60 \\
60\end{array}$ & $\begin{array}{l}2.8 \\
3.2 \\
3.9\end{array}$ & $\begin{array}{l}0.3 \\
0.3 \\
0.3\end{array}$ & $\begin{array}{l}0.9 \\
1.5 \\
4.2\end{array}$ & $\begin{array}{l}0.2 \\
0.2 \\
0.4\end{array}$ \\
\hline Rhodomonas baltica & $\begin{array}{l}2.10 \\
3.15 \\
4.20\end{array}$ & $\begin{array}{l}60 \\
60 \\
60\end{array}$ & $\begin{array}{l}3.6 \\
3.4 \\
2.8\end{array}$ & $\begin{array}{l}0.3 \\
0.3 \\
0.2\end{array}$ & $\begin{array}{l}0.2 \\
0.6 \\
0.5\end{array}$ & $\begin{array}{l}0.1 \\
0.1 \\
0.1\end{array}$ \\
\hline
\end{tabular}

Table 3. Univariate ANOVA for Synchaeta cecilia valentina average lifespan $(L S)$ and average number of offspring per female $\left[R_{0}\right]$ with respect to the 5 different algal treatments and the 3 different food levels

\begin{tabular}{|lcrrrrr|}
\hline Effect & df & \multicolumn{2}{c}{$L S$} & \multicolumn{2}{c|}{$R_{0}$} \\
& & $F$ & $p$ & $F$ & $p$ \\
\hline Alga (A) & 4,884 & 60.9 & 0.000 & 181.3 & 0.000 \\
Food level (F) & 2,884 & 2.1 & 0.121 & 29.3 & 0.000 \\
A $\times$ F interaction & 8,884 & 7.7 & 0.000 & 7.0 & 0.000 \\
& & & & & \\
\hline
\end{tabular}

cultured with T. chuii. Cryptomonas sp. increased the proportion of n-3 long-chain PUFA such as 22:5n-3 and 22:6n-3. In general, n-6 fatty acids were less variable than n-3 among the different dietary groups.

The first discriminant function explained more than $72 \%$ of total variance with a significance level of 0.0116 , whereas both first and second discriminant functions explained a cumulated percentage of variance over $90 \%$, although the second function was only significant at $\mathrm{p}<0.15$. The centroids for these

$R$. salina and Cryptomonas sp. present similar values for $R_{0}$ at low and intermediate food concentrations although the lower $T_{c}$ obtained with the alga Cryptomonas sp. makes its $r$ greater.

Table 4 shows the percentage of the fatty acids from the total lipid of rotifers fed the different algal treatments. Saturated fatty acids accounted for 34 to $40 \%$ of total fatty acids, whereas monoenes represented 15 to $23 \%$, and polyunsaturated fatty acids (PUFA) constituted 20 to $29 \%$. Main fatty acids were 16:0 (which ranged from 17 to $22 \%$ ), $18: 0$ (10 to $12 \%$ ), and $18: 1$ (8.5 to $12 \%$ ). In certain groups (Tetraselmis spp.) $18: 3 n-3$ was moderately abundant ( 5 to $9 \%$ ). Eicosapentaenoic acid, 20:5n-3, was markedly lower in Rhodomonas baltica fed rotifers (less than 3\%), whereas 22:6n-3 was found in higher proportion in Cryptomonas sp. $(4.9 \%)$ and $R$. salina $(3.4 \%)$. T. chuii showed a high proportion of shorter chain fatty acids $(<14)$. In closer detail, 14:0 was higher in rotifers cultured with Rhodomonas spp. and Cryptomonas sp, 16:0 higher when $T$. suecica and Tetraselmis sp. were used as food, 16:1 and 16:3 were higher in rotifers fed $R$. baltica, as was 20:1 in those first 2 discriminant functions are plotted in Fig. 3. The discriminant analysis model easily separated the algal treatments corresponding to the 2 main groups of algae: Tetraselmis spp, versus Cryptomonas-Rhodomonas spp. in the first discriminant function.

\section{DISCUSSION}

Synchaeta cecilia valentina showed positive growth when fed Tetraselmis sp., T. chuii and Crytomonas sp. at the 3 experimental concentrations. With the alga Rhodomonas salina the rotifer grew only with the 2 highest food concentrations. Although no growth was obtained with any of the experimental concentrations of $R$. baltica, the rotifer grew in $500 \mathrm{ml}$ cultures at $5.55 \mu \mathrm{g} \mathrm{ml}^{-1}$ dry wt, which suggests that this microalga can also be used as food when provided at adequate concentrations. All these algae, together with $T$. suecica (Oltra \& Todoli 1997), are, until now, the bestknown food for use in the culture of $S$. cecilia valentina. 


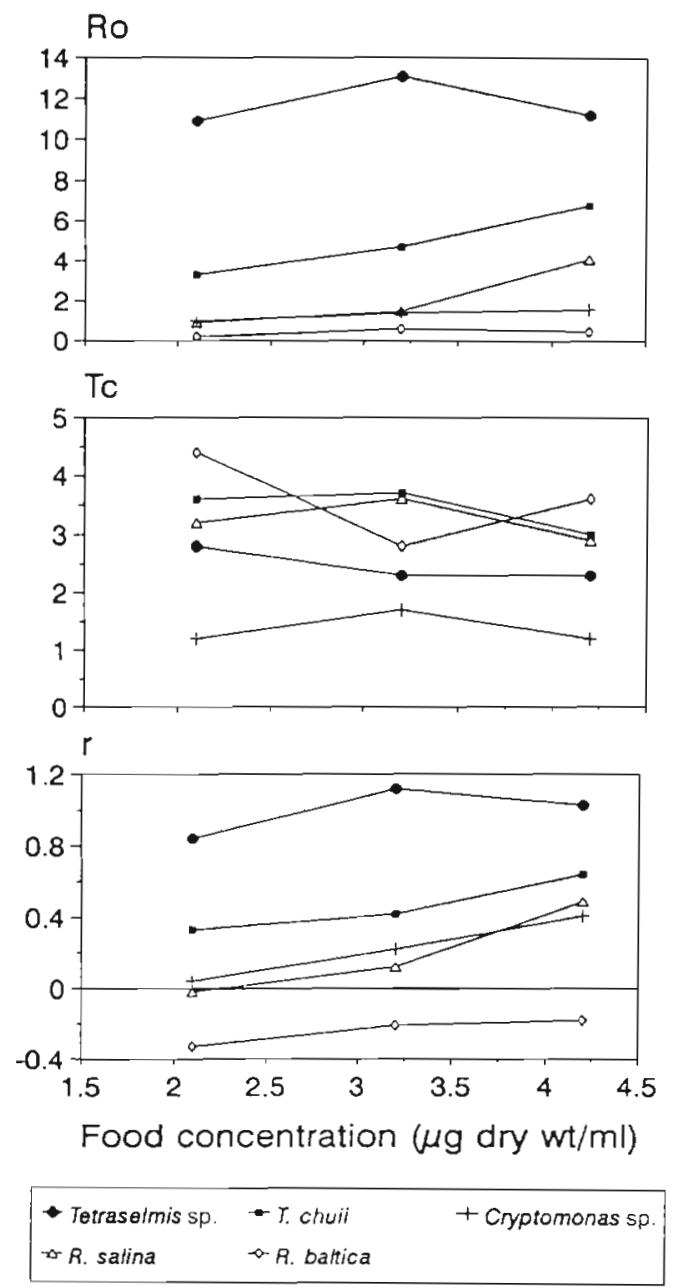

Fig. 2. Effect of algae type and food concentration on net reproductive rate $\left(R_{0}\right)$, cohort generation time $\left(T_{c}\right)$ and intrinsic growth rate $(r)$ of Synchaeta cecilia valentina

The Cryptophyceae algae seem to give the best results for culturing species of the Synchaeta genus, as they do in fresh water (Stemberger 1981, May 1987, Gilbert \& Schreiber 1998) and as in previous research work in salt water (Egloff 1988). The marine species $S$. cecilja valentina does not, in fact, survive in the long term with cultures of only 1 alga, unless it is Cryptomonas sp. or another unindentified cryptophyte (strain WH2), which resulted in 2 positive assays out of a total of 37 with algae from 7 groups (Egloff 1988). S. hutchingsi, also a marine species, has been cultivated with a mixture of diatoms and flagellates (among others the alga Tetraselmis chuii), but not with algal monocultures (Brownell 1988). Notwithstanding this, it has been possible to cultivate $S$. cecilia valentina successfully not only with cryptophyte algae cultures, but also with cultures of chlorophytes (Tetraselmis spp.).

The $r$ values obtained with Tetraselmis $\mathrm{sp}$, averaged $1.00 \mathrm{~d}^{-1}$, with a maximum of $1.12 \mathrm{~d}^{-1}$, and are higher than those obtained with other algae (Table 5, Fig. 2). Rotifers cultured with Tetraselmis sp. also showed the highest lifespan and net reproductive rate. The $r$ values can be considered high when compared with values obtained for other rotifer cultures in salt water at the same temperature $\left(20^{\circ} \mathrm{C}\right)$. Egloff (1986) obtained $r$ of $0.63 \mathrm{~d}^{-1}$ feeding $S$. cecilia valentina with Heterocapsa pygmaea (23 ppt salinity). With the species Brachionus plicatilis $r$ values range between 0.1 and $0.5 \mathrm{~d}^{-1}$ in life tables at 24 ppt (Miracle \& Serra 1989), as in mass cultures for aquaculture (Lubzens et al. 1989, Caric et al. 1993).

Nevertheless, the average lifespan of Synchaeta cecilia valentina is clearly lower than that of other rotifers cultured at the same temperature. Serra et al. (1994) obtained values of 8.1 and $9.9 \mathrm{~d}$ for Brachionus plicatilis fed Tetraselmis suecica (24 ppt) and SchmidAraya (1991) reported values from 11.6 to $16.7 \mathrm{~d}$ (18 ppt) for the same rotifer fed on Brachiomonas submarina and from 11.5 to $12.4 \mathrm{~d}$ for the rotifer Encentrum linnhei cultured under the same conditions.

When compared with the cultures using Tetraselmis $\mathrm{sp}$. as food, the $r$ values decrease with $T$. suecica, $T$. chuii, Cryptomonas sp. and Rhodomonas salina. The average value of $R_{0}$ decreases in a similar way to $r$ except in the cultures fed with Cryptomonas sp. The average $R_{0}$ obtained with this alga is 1.4 , lower than the value obtained for $R$. salina, although the generation time is also short (1.4 d), which increases the average value of $r$ slightly with respect to $R$. salina.

The selection of the assayed food concentrations was based on preliminary assays in which it was evident that Synchaeta cecilia valentina shows a high sensitivity to excessive food concentrations. At $20^{\circ} \mathrm{C}$ and using Tetraselmis suecica as food, $R_{0}$ reduces when the algal concentration increases by $66 \%\left(2.10\right.$ to $3.49 \mu \mathrm{g} \mathrm{ml} \mathrm{m}^{-1}$ dry wt), whereas exactly the opposite happens at $24^{\circ} \mathrm{C}$ (Oltra \& Todoli 1997). Optimum thresholds of food concentration have been observed in several freshwater species of rotifers (Stemberger \& Gilbert 1985) as well as in the euryhaline species Brachionus plicatilis and Encentrum linnhei (Schmid-Araya 1991).

Food concentration does not have a significant effect on $L S$, but does on $R_{0}$ (Table 3 ). With some algae, $L S$ increases with food concentration (Rhodomonas salina, Cryptomonas sp., Tetraselmis chuii), whereas a decrease is produced with others ( $R$. baltica, Tetraselmis $\mathrm{sp}$ ) (Table 2). $R_{0}$ tends to increase with food concentration (Table 5). Tetraselmis $\mathrm{sp}$. produces the best results at medium food concentration (higher $R_{0}$ and $r$, and lower $T_{c}$ ). From this point of view, Tetraselmis sp. is the most adequate diet. The remainder of the algae produce an increase in $R_{0}$ and a decrease in $T_{c}$, with $r$ increasing at higher food concentrations. Whether $r$ would continue to increase at higher food concentrations has yet to be studied. 
Table 4. Main fatty acids (FA) from the total lipids of Synchaeta cecilia valentina cultured with different microalgae. Values are expressed as percentages of total fatty acids (mean of 3 replicates). nd: not detected; 0.0 : mean values <0.09. PUFA: polyunsaturated fatty acids; HUFA: PUFA longer than $20 \mathrm{C}$

\begin{tabular}{|c|c|c|c|c|c|c|c|c|c|c|c|c|}
\hline \multirow[t]{3}{*}{ FA } & \multicolumn{12}{|c|}{ Algal treatment } \\
\hline & \multicolumn{2}{|c|}{$\begin{array}{c}\text { Tetraselmis } \\
\text { suecica }\end{array}$} & \multicolumn{2}{|c|}{$\begin{array}{c}\text { Tetraselmis } \\
\text { chuii }\end{array}$} & \multicolumn{2}{|c|}{$\begin{array}{c}\text { Tetraselmis } \\
\text { sp. }\end{array}$} & \multicolumn{2}{|c|}{$\begin{array}{c}\text { Cryptomonas } \\
\text { sp. }\end{array}$} & \multicolumn{2}{|c|}{$\begin{array}{c}\text { Rhodomonas } \\
\text { salina }\end{array}$} & \multicolumn{2}{|c|}{$\begin{array}{c}\text { Rhodomonas } \\
\text { baltica }\end{array}$} \\
\hline & Mean & $\mathrm{SD}$ & Mean & $\mathrm{SD}$ & Mean & SD & Mean & $\mathrm{SD}$ & Mean & $\mathrm{SD}$ & Mean & $\mathrm{SD}$ \\
\hline$<14$ & 1.2 & 0.9 & 3.1 & 1.7 & 2.9 & 0.7 & 1.5 & 0.3 & 0.5 & 0.0 & 1.4 & 0.2 \\
\hline 14:0 & 2.2 & 0.4 & 1.8 & 0.3 & 2.1 & 0.4 & 3.3 & 0.4 & 3.8 & 0.3 & 2.9 & 0.2 \\
\hline $14: 1$ & 0.4 & 0.0 & 0.6 & 0.2 & 1.3 & 0.7 & 0.7 & 0.2 & 0.9 & 0.1 & 0.8 & 0.2 \\
\hline $15: 0$ & 1.5 & 0.6 & 1.2 & 0.6 & 1.0 & 0.1 & 1.7 & 0.2 & 1.4 & 0.2 & 2.0 & 0.5 \\
\hline $15: 1$ & 0.3 & 0.1 & 0.3 & 0.0 & 0.3 & 0.1 & 0.4 & 0.0 & 0.4 & 0.1 & 0.5 & 0.2 \\
\hline $16: 0$ & 22.2 & 0.1 & 19.8 & 0.8 & 21.0 & 1.5 & 19.9 & 1.0 & 19.8 & 1.5 & 16.8 & 1.4 \\
\hline $16: 1^{a}$ & 5.1 & 2.1 & 2.5 & 0.8 & 2.7 & 0.8 & 3.8 & 0.3 & 3.9 & 0.7 & 7.6 & 2.4 \\
\hline $16: 2$ & 0.3 & 0.1 & 0.2 & 0.2 & 0.1 & 0.0 & 0.4 & 0.0 & 0.2 & 0.1 & 0.5 & 0.2 \\
\hline $17: 0$ & 1.0 & 0.1 & 1.2 & 0.3 & 1.1 & 0.4 & 1.4 & 0.0 & 1.3 & 0.0 & 1.2 & 0.3 \\
\hline $16: 3$ & 0.6 & 0.5 & 0.4 & 0.2 & 0.3 & 0.1 & 0.7 & 0.1 & 0.6 & 0.1 & 1.0 & 0.3 \\
\hline $16: 4$ & nd & & nd & & nd & & 0.2 & 0.1 & 0.2 & & nd & \\
\hline $18: 0$ & 12.0 & 1.8 & 11.5 & 2.8 & 12.9 & 2.0 & 11.7 & 0.7 & 11.4 & 0.1 & 9.6 & 1.0 \\
\hline $18: 1^{a}$ & 10.8 & 0.7 & 9.5 & 0.3 & 10.8 & 2.5 & 8.5 & 1.9 & 10.7 & 0.5 & 12.2 & 3.4 \\
\hline $18: 2 n-6$ & 6.0 & 3.7 & 3.8 & 0.5 & 4.2 & 0.2 & 2.8 & 0.7 & 4.1 & 1.5 & 5.4 & 2.6 \\
\hline $18: 3 n-6$ & 0.2 & & nd & & nd & & nd & & $\mathrm{nd}$ & & nd & \\
\hline $18: 3 n-3$ & 4.8 & 1.4 & 9.1 & 5.0 & 6.9 & 3.8 & 3.3 & 1.5 & 2.8 & 0.1 & 2.0 & 1.2 \\
\hline $18: 4 n-3$ & 3.3 & 0.8 & 1.7 & 1.0 & 1.7 & 1.0 & 3.4 & 0.9 & 2.8 & 0.0 & 2.3 & 1.8 \\
\hline $20: 0$ & 0.8 & 0.2 & 0.6 & 0.2 & 0.6 & 0.1 & 0.7 & 0.0 & 0.6 & 0.0 & 0.6 & 0.2 \\
\hline $20: 1^{\mathrm{d}}$ & 1.8 & 0.4 & 2.1 & 0.8 & 1.6 & 0.5 & 1.2 & 0.2 & 0.6 & 0.0 & 0.6 & 0.3 \\
\hline $20: 2 n-6$ & 1.0 & 0.4 & 1.9 & 0.4 & 1.7 & 0.3 & 1.4 & 0.2 & 1.9 & 0.5 & 1.9 & 1.3 \\
\hline $20: 3 n-6$ & 0.4 & 0.2 & 0.7 & 0.3 & 0.6 & 0.4 & 0.6 & 0.1 & 0.6 & 0.0 & 0.4 & 0.1 \\
\hline $20: 4 n-6$ & 1.0 & 0.6 & 0.8 & 0.1 & 0.9 & 0.3 & 0.7 & 0.8 & 0.3 & 0.3 & 0.2 & 0.0 \\
\hline $20: 3 n-3$ & 0.9 & 0.4 & 1.6 & 1.1 & 1.1 & 0.6 & 1.0 & 0.4 & 0.7 & 0.0 & 0.3 & 0.3 \\
\hline $20: 4 n-3$ & 1.0 & 0.3 & 0.7 & 0.4 & 1.0 & 0.5 & 1.1 & 0.5 & 1.1 & 0.2 & 0.9 & 1.1 \\
\hline $20: 5 n-3$ & 6.8 & 2.0 & 5.7 & 2.9 & 4.4 & 1.7 & 7.6 & 2.0 & 5.0 & 0.0 & 2.6 & 1.7 \\
\hline $22: 0$ & 0.8 & 0.5 & 0.5 & 0.2 & 0.7 & 0.3 & 0.7 & 0.1 & 0.8 & 0.5 & 0.5 & 0.1 \\
\hline $22: 1^{\mathrm{a}}$ & 0.9 & 0.3 & 1.1 & 0.5 & 0.9 & 0.3 & 0.5 & 0.1 & 0.7 & 0.5 & 1.6 & 1.1 \\
\hline $22: 2 n-6$ & 0.9 & 0.3 & 0.5 & 0.2 & 0.5 & 0.2 & 0.4 & 0.0 & 0.2 & 0.1 & 0.2 & 0.1 \\
\hline $22: 4 n-6$ & nd & & nd & & nd & & nd & & 0.3 & & 0.1 & \\
\hline $22: 5 n-6$ & 0.1 & & 0.3 & & 0.4 & 0.3 & 0.3 & & 1.0 & & nd & \\
\hline $22: 5 n-3$ & 0.2 & 0.1 & 0.2 & 0.1 & 0.1 & 0.1 & 0.6 & 0.2 & 0.4 & 0.0 & 0.6 & 0.1 \\
\hline $22: 6 n-3$ & 0.7 & 0.3 & 0.7 & 0.3 & 1.1 & 0.1 & 4.9 & 1.5 & 3.4 & 0.1 & 1.8 & 1.2 \\
\hline Saturates & 40.5 & 2.6 & 36.6 & 5.0 & 39.4 & 3.3 & 39.3 & 0.9 & 39.1 & 2.6 & 33.7 & 2.6 \\
\hline Monoenes & 19.2 & 2.2 & 16.2 & 0.6 & 17.5 & 3.4 & 15.0 & 2.2 & 17.2 & 0.9 & 23.3 & 5.8 \\
\hline PUFA & 28.0 & 2.5 & 28.3 & 10.0 & 24.9 & 7.5 & 28.9 & 6.4 & 24.8 & 0.5 & 20.0 & 5.7 \\
\hline$n-3$ & 17.8 & 5.2 & 19.9 & 10.5 & 16.2 & 7.6 & 21.9 & 6.6 & 16.2 & 0.1 & 10.3 & 7.3 \\
\hline$n-6$ & 9.3 & 2.2 & 7.9 & 0.2 & 8.3 & 0.4 & 5.8 & 0.8 & 7.7 & 0.3 & 8.2 & 1.9 \\
\hline HUFA n-3 & 9.6 & 3.1 & 9.0 & 4.7 & 7.7 & 2.8 & 15.2 & 4.5 & 10.6 & 0.2 & 5.9 & 4.4 \\
\hline HUFA $n-6$ & 3.3 & 1.4 & 4.1 & 0.6 & 4.1 & 0.6 & 3.0 & 0.8 & 3.6 & 1.1 & 2.8 & 1.2 \\
\hline dha/epa & 0.1 & & 0.1 & & 0.3 & & 0.6 & & 0.7 & & 0.7 & \\
\hline
\end{tabular}

There are, also, other aspects that require further studies. One of these is the contradictory result obtained in the cultures of Synchaeta cecilia valentina with Rhodomonas baltica under different conditions in $500 \mathrm{ml}$ cultures. One possible explanation for this may lie in the greater concentration of food in the $500 \mathrm{ml}$ cultures, and the use of aeration to keep the alga suspended. Another related aspect is whether all the algae were equally available for the rotifers. We have found no reasons to think otherwise considering that all the algae assayed are motile, that daily renewal of food involves necessarilly homogenization and that no irregularities were detected in any of the treatments. Besides, the results of the $500 \mathrm{ml}$ cultures followed the same trends as those of the life tables, i.e., better growth with algae of Tetraselmis genus than with Cryptomonas and Rhodomonas.

The fatty acid composition of the rotifers fed different algal diets showed high variability within the same dietary treatment. This, together with the fairly in- 


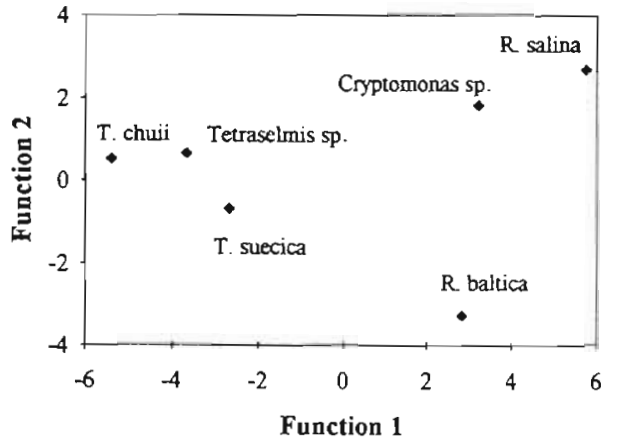

Fig. 3. Centroids for first 2 discriminant functions of fatty acid data from total lipid of the rotifer Synchaeta cecilia valentina cultured with different microalgae

significant differences found among the dietary groups, resulted in few statistically significant differences for many fatty acids. Even though the fatty acid composition of algal species is variable and depends on many phenotypic factors, some trends can be identified. Generally speaking, the main difference between Chlorophyceae and Cryptophyceae is the higher concentration of n-3 PUFA in the latter. Both Cryptomonas sp. and Rhodomonas spp. are rich in $18: 4 n-3$ and $18: 3 n-3$ (23 to $31 \%$ ), and moderate in $20: 5 n-3$ ( 8 to $12 \%$ ) and $22: 6 n-3$ ( 4 to $7 \%$ ). Their 16:0 level is lower than in Tetraselmis species, which have higher $16: 4 n-3(16 \%)$, high $18: 3 n-3(18$ to $22 \%)$ and moderate $20: 5 n-3(4 \%)$, together with very low, if any, 22:6n-3 (Renaud et al. 1999, see also Pohl \& Zurheide 1979). To a certain extent, this is reflected in the fatty acid profile of the rotifers fed both kinds of algae.

It has been postulated that the fatty acid composition of rotifers resembles that of their algal food (Ben-
Amotz et al. 1987, Frolov et al. 1991). This may be true in general terms, but a metabolic transformation by the rotifers has also been suggested (Frolov et al. 1991). A deeper analysis of some of the data available reveals a particularly striking lack of correspondence between some of the percentages of certain fatty acids in the algal food and in the rotifers. A good example can be found in the data reported by Ben-Amotz et al. (1987) regarding the fatty acid profiles of Brachionus plicatilis when cultured with different algal species and the corresponding fatty acid profiles of the microalgal feed species. Chaetoceros gracilis, which had $4.1 \%$ of their total fatty acids as 20:5n-3, produced levels of $2.8 \%$ of the same fatty acid in the rotifers, whereas $\mathrm{Nan}$ nochloropsis salina, rich in 20:5n-3 (14.8\%), produced rotifers with only $6.3 \%$ of the same fatty acid. Isochrysis galbana, relatively rich in 22:6n-3 (3.4\%), produced rotifers with the highest $22: 6 n-3$ proportion, but other algae lacking this fatty acid (Chaetoceros gracilis) also induced the presence of $22: 6 n-3(1 \%)$ in the rotifers. The same lack of direct correlation can be found for rotifers fed other algae for different fatty acids in the same work and in others (Frolov et al. 1991).

Considering these facts, together with the abundant variability among replicate cultures of the same microalgal fed species, it seemed to us to be more accurate to use a multivariate chemometric method (see Navarro et al. 1995) to study the effect of algal food. The use of chemometric techniques such as the multivariate discriminant analysis used here does, however, produces clear separation between the rotifers fed on the 2 main algal groups: Chlorophyceae (Tetraselmis species) and Cryptophyceae (Rhodomonas and Cryptomonas species). This effect is clear in Fig. 3 with the presence of 2 main groups of rotifers fed the 2 main classes of algae.

Table 5. Mean values of demographic parameters (average lifespan, $L S$, average number of offspring per female, $R_{0}$, cohort generation time $\left[T_{c}\right]$ and intrinsic growth rate $[r]$ ) for each experimental alga and food concentration. Table includes results from previous assays with Tetraselmis suecica at the same temperature and salinity (Oltra \& Todolí 1997)

\begin{tabular}{|c|c|c|c|c|c|c|c|c|c|c|}
\hline & $\mathrm{n}$ & LS & $\mathrm{SE}$ & $R_{0}$ & $\mathrm{SE}$ & $\mathrm{n}$ & $T_{r}$ & $\mathrm{SE}$ & $r$ & $\mathrm{SE}$ \\
\hline \multicolumn{11}{|l|}{ Alga } \\
\hline Tetraselmis sp. & 180 & 5.1 & 0.1 & 11.7 & 0.3 & 3 & 2.5 & 0.1 & 1.00 & 0.07 \\
\hline T. chuii & 179 & 4.5 & 0.2 & 4.9 & 0.3 & 3 & 3.4 & 0.2 & 0.46 & 0.07 \\
\hline T. suecica ${ }^{\mathrm{a}}$ & 144 & 4.2 & 0.3 & 7.7 & 0.5 & 2 & 3.0 & 0.1 & 0.68 & 0.02 \\
\hline Cryptomonas sp. & 180 & 1.8 & 0.1 & 1.4 & 0.1 & 3 & 1.4 & 0.1 & 0.22 & 0.08 \\
\hline R. salina & 180 & 3.3 & 0.2 & 2.2 & 0.2 & 3 & 3.2 & 0.2 & 0.20 & 0.12 \\
\hline R. baltica & 180 & 3.3 & 0.2 & 0.4 & 0.1 & 3 & 3.6 & 0.4 & -0.24 & 0.03 \\
\hline \multicolumn{11}{|c|}{ Food concentration ( $\mu \mathrm{g} \mathrm{ml^{-1 }}$ dry wt) } \\
\hline 2.10 & 300 & 3.3 & 0.2 & 3.3 & 0.3 & 5 & 2.8 & 0.5 & 0.33 & 0.18 \\
\hline 3.15 & 299 & 3.6 & 0.1 & 4.2 & 0.3 & 5 & 2.8 & 0.3 & 0.33 & 0.20 \\
\hline 4.20 & 300 & 3.6 & 0.1 & 4.9 & 0.3 & 5 & 2.6 & 0.4 & 0.48 & 0.18 \\
\hline
\end{tabular}


In summary, it has been possible to culture the marine rotifer Synchaeta cecilia valentina with 5 different monoalgal diets. The effect that these diets and different food levels have on several demographic parameters of this rotifer has been determined. Tetraselmis sp. provided the best results. The comparison of our data on fatty acids in S. cecilia valentina fed different algal food with other information available on the fatty acids of Brachionus plicatilis cultured with microalgal feed species leads us to conclude that cultures of both rotifers should have similar nutritional value regardless of their marine 'versus' mixohaline ecological origin.

Acknowledgements. This study was supported by Spanish Culture and Education Ministry, project MAR98-0871-C0201/02. We thank A. Gómez and M. Serra for their suggestions.

\section{LITERATURE CITED}

Ben Amotz A, Fishler R, Schneller A (1987) Chemical composition of dietary species of marine unicellular algae and rotifers with emphasis on fatty acids. Mar Biol 95:31-36

Brownell CL (1988) A new pelagic marine rotifer from the southern Benguela, Synchaeta hutchingsi, n. sp., with notes on its temperature and salinity tolerance and methods of culture. Hydrobiologia 162:225-233

Carey JM (1993) Applied demography for biologists. Oxford University Press, New York

Caric M, Sanko-Njire J, Skaramuca B (1993) Dietary effects of different feeds on the biochemical composition of the rotifer (Brachionus plicatilis Müller). Aquaculture 110:141-150

Egloff DA (1986) Effects of Olisthodiscus luteus on the feeding and reproduction of the marine rotifer Synchaeta cecilia. J Plankton Res 8:263-274

Egloff DA (1988) Food and growth relations of the marine microzooplankter, Synchaeta cecilia (Rotifera). Hydrobiologia 157:129-141

Frolov AV, Pankov SL, Geradze KN, Pankova SA, Spektorova LV (1991) Influence of the biochemical composition of food on the biochemical composition of the rotifer Brachionus plicatilis. Aquaculture 97:181-202

Gilbert JJ, Schreiber DK (1998) Asexual diapause induced by food limitation in the rotifer Synchaeta pectinata. Ecology 79:1371-1381

Guillard RL, Ryther JH (1962) Studies of marine plankton diatoms. I. Cyclotella nana Hustedt and Detonula confervacea (Cleve). Can J Microbiol 8:229-239

Lubián LM, Yúfera M (1989) Colección de cepas de microalgas del Instituto de Ciencias Marinas de Andalucía

Editorial responsibility: Otto Kinne (Editor),

Oldendorf/Luhe, Germany
(CSIC). In Yúfera $M$ (ed) Acuicultura intermareal. Inst Cien Mar Andalucía, Cádiz, p 69-78

Lubzens E, Tandler A, Minkoff G (1989) Rotifers as food in aquaculture. Hydrobiologia 186/187:387-400

Maruyama I, Nakao T, Shigeno I, Ando Y, Hirayama K (1997) Application of unicellular algae Chlorella vulgaris for the mass-culture of marine rotifer Brachionus. Hydrobiologia 358:133-138

May L (1987) Culturing freshwater, planktonic rotifers on Rhodomonas minuta var. nannoplanctica Skuja and Stichococcus bacillaris Nägeli. J Plankton Res 9:1217-1223

Miracle MR, Serra M (1989) Salinity and temperature influence in rotifer life history characteristics. Hydrobiologia 186/186:81-102

Navarro JC, Amat F, Sargent JR (1992) Fatty acid composition of coastal and inland Artemia sp. populations from Spain. Aquaculture 102:219-230

Navarro JC, McEvoy LA, Amat F, Sargent JR (1995) Effects of diet on fatty acid composition of body zones in larvae of the sea bass Dicentrarchus labrax: a chemometric study Nar Biol 124:177-183

Oltra R, Todolí R (1997) Effects of temperature, salinity and food level on the life history traits of the marine rotifer Synchaeta cecilia valentina, n. subsp. J Planktorn Res 19 693-702

Pohl P, Zurheide F (1979) Fatty acids and lipids of marine algae and the control of their biosynthesis by environmental factors. In: Hoppe HA, Levring $T$, Tanaka $Y$ (eds) Marine algae in pharmaceutical science. Walter de Gruyter, Berlin, p 473-523

Pourriot R (1965) Récherches sur l'écologie des Rotifères. Vie Milieu Suppl 21:1-224

Renaud SM, Thinh L, Parry DL (1999) The gross chemical composition and fatty acid composition of 18 species of tropical Australian microalgae for possible use in mariculture. Aquaculture 170:147-159

Rezeq TA, James CM (1987) Production and nutritional quality of the rotifer Brachionus plicatilis fed marine Chlorella sp. at different cell densities. Hydrobiologia 147:257-261

Schmid-Araya JM (1991) The effect of food concentration on the life histories of Brachionus plicatilis (OF $\mathrm{F}$ ) and Encentrum linnhei Scott. Arch Hydrobiol 121:87-102

Segers H (1995) Nomenclatural consequences of some recent studies on Brachionus plicatilis (Rotifera, Brachionidae). Hydrobiologia 313/314:121-122

Serra M. Carmona MJ, Miracle MR (1994) Survival analysis of three clones of Brachionus plicatilis (Rotifera). Hydrobiologia 227:97-105

Snell TW, Janssen CR (1995) Rotifers in ecotoxicology: a review. Hydrobiologia 313/314:231-247

Stemberger RS (1981) A general approach to the culture of planktonic rotifers. Can J Fish Aquat Sci 38:721-724

Stemberger RS, Gilbert JJ (1985) Body size, food concentration, and population growth in planktonic rotifers. Ecology $66: 1151-1159$

Submitted: June 9, 1999; Accepted: September 22, 1999

Proofs received from author(s): February 11, 2000 